\title{
DỤ๋ TÍNH KHÍ HẬU TƯƠNG LAI Ở LỦU VỤC SÔNG BA TRONG BỐI CẢNH TÍNH KHÔNG CHẮC CHẮN CỦA CÁC MÔ HÌNH KHÍ HậU
}

\author{
Phan Thị Thùy Dương ${ }^{1}$, Vũ Thị Vân Anh ${ }^{1,2}$, Nguyễn Thị Tuyết ${ }^{1}$
}

Tóm tắt: Bài báo đánh giá tính không chắc chắn trong kết quả các mô phỏng biến khi hậu ở luu vưc sông $B a$ (LVSB) của 4 nhóm mô hình: GCMs, RCMs, GCMs được hiệu chỉnh sai số hệ thống (BC-GCMs); RCMs được hiệu chinh sai số hệ thống (BC-RCMs). Phương pháp đánh giá tính không chắc chắn trong thời kỳ nền dựa trên phân tích các sai số thống kê. Việc so sánh biến trình các tháng trong năm giữa các kết quả mô phỏng được tiến hành với số liệu quan trắc tại 3 trạm đo nhiẹt độ và 6 trạm đo mưa. Việc đánh giá dụ tính khi hậu LVSB trong tưong lai bằng cách phân tích độ lệch chuẩn (SD) của kết quả dụ tính khi hậu tại các bách phân vị khác nhau. Sau đó, bài báo lựa chọn nhóm mô hình có tính không chắc chắn thấp nhất để dụ tính khí hậu tưong lai trên toàn LVSB. Kết quả cho thấy, nhóm BC-RCMs có tính không chắc chắn nhỏ nhất, do đó bài báo lựa chọn nhóm $B C$ RCMs để dụ tính khí hậu tuoong lai trên LVSB. Đối với các biến nhiệt độ, mức tăng dao động tù 0$4,8^{\circ} \mathrm{C}$ so với thời kỳ nền ở tất cả các thời kỳ, tăng nhiều hơn ở khu vưc có nền nhiệt độ trung bình cao hơn. Đối với biến lượng mura, mức tăng tại các trạm có sự khác nhau, xu thế tăng nhiều hơn ở nhũng khu vưc có lượng mưa năm lớn, mưc tăng lương mura mùa mura thấp hơn so với mùa khô.

Từ khóa: Tính không chắc chăn, Kết quả mô hình khỉ hậu, Lưu vục sông Ba, Biến đổi khí hậu.

\section{Ban Biên tập nhận bài: 5/7/2019 Ngày phản biện xong: 22/8/2019 Ngày đăng bài: 25/09/2019}

\section{Mở đầu}

Trong nghiên cứu về tác động của biến đổi khí hậu $(\mathrm{BĐKH})$ đến hệ thống tài nguyên nước (TNN) trên lưu vực sông, cách tiếp cận từ trên xuống (top-down) thường được sử dụng phổ biến [24]. Cách tiếp cận này được đưa ra dưới dạng khung phân tích tại Hội nghị các thành viên lần thứ nhất trong khuôn khổ Công ước khung của Liên Hợp quốc về BĐKH vào năm 1995 [9]. Theo đó, việc đánh giá tác động của $\mathrm{B} Đ K H$ bắt đầu với dự tính khí hậu từ các mô hình khí hậu toàn cầu (GCMs). Các kết quả dự tính khí hậu sau đó được chi tiết hóa thống kê hoặc động lực bằng mô hình khí hậu khu vực $(\mathrm{RCMs})$ và hiệu chỉnh sai số hệ thống để đưa kết quả từ RCMs gần hơn với số liệu quan trắc. Sau đó, các biến khí hậu được sử dụng làm đầu vào của mô hình thủy văn và tiếp theo là mô hình thủy lực hoặc/và

${ }^{1}$ Đại học Tài nguyên và Môi trường TP.HCM

${ }^{2} Đ a$ a hoc Bách khoa TP.HCM

Email:pttduong@hcmunre.edu.vn các mô hình hệ thống TNN khác. Sau khi dự tính được sự thay đổi của TNN trên lưu vực trong bối cảnh BĐKH, các đề xuất về các giải pháp thích ứng cho lưu vực nghiên cứu được đưa ra $[6,10$, 22, 23, 25]. Có thể nói, cách tiếp cận top-down đã cung cấp được các thông tin về tác động tiềm tàng của $\mathrm{BĐKH}$ đối với một lưu vực sông cụ thể bằng cách sử dụng các kịch bản phát triển kinh tế xã hội, bảo vệ môi trường và kịch bản nồng độ khí nhà kính khác nhau trong tương lai [8]. Tuy nhiên, kết quả của cách tiếp cận này đã gây ra khó khăn cho các nhà hoạch định chính sách trong việc ra quyết định về các giải pháp thích ứng do sự không chắc chắn từ các kết quả dự tính khí hậu [5, 7, 15, 16, 21].

Sự không chắc chắn trong kết quả đánh giá tác động của $\mathrm{BĐKH}$ theo cách tiếp cận từ trên xuống đến từ nhiều nguồn khác nhau. Nguồn gốc đầu tiên là do sự phụ thuộc vào các kịch bản phát triển kinh tế-xã hội $(\mathrm{KT}-\mathrm{XH})$ và phát thải khí nhà kính (KNK) trong tương lai, bao gồm dân số, 
quy mô của các ngành kinh tế, sự phát triển về khoa học kỹ thuật và các chính sách về bảo vệ môi trường $[12,24]$. Nguồn gốc tiếp theo liên quan đến quá trình mô hình hóa, bao gồm mô hình khí hậu GCMs (cùng các kỹ thuật chi tiết hóa và hiệu chỉnh sai số hệ thống) và các mô hình mô phỏng tác động đến hệ thống như mô hình thủy văn, mô hình thủy lực, mô hình tối ưu hóa... [10,15]. Cuối cùng là sự dao động khí hậu tự nhiên ở phạm vi địa phương cũng là nguồn gốc góp phần tiếp theo cho chuỗi không chắc chắn trong kết quả đánh giá tác động của $\mathrm{B} Đ K H$ theo cách tiếp cận từ trên xuống [15]. Nhiều nghiên cứu đã định lượng tính không chắc chắn từ các nguồn khác nhau, kết luận đưa ra là tính không chắc chắn trong quá trình dự tính khí hậu từ GCMs, các quá trình chi tiết hóa và hiệu chỉnh sai số hệ thống là lớn nhất, trong khi các nguồn khác cũng rất đáng kể [10, 13, 14, 18, 19].

Lưu vực sông $\mathrm{Ba}$ (LVSB) là lưu vực sông lớn nhất miền Trung Việt Nam với tổng diện tích tự nhiên là $13.417 \mathrm{~km}^{2}$, trải dài từ $12^{\circ} 55^{\prime}$ ' đến $14^{\circ} 58^{\prime}$ vĩ độ Bắc và $108^{\circ} 00^{\prime}$ đến $109^{\circ} 55^{\prime}$ ' kinh độ Đông. Phần lớn lưu vực thuộc ranh giới các tỉnh Gia Lai, Đăk Lăk và Phú Yên. Khí hậu trên LVSB chịu ảnh hưởng của dãy núi Trường Sơn, bao gồm 3 vùng khí hậu khá rõ rệt: vùng Đông Trường Sơn, vùng Tây Trường Sơn và vùng Trung gian. So với các lưu vực sông khác ở Việt Nam, LVSB có tài nguyên nước hạn (TNN) hạn chế với mô đun dòng chảy trung bình hàng năm vào khoảng $25,72 \mathrm{1} / \mathrm{s} \cdot \mathrm{km}^{2}$. Hơn nữa, do lượng mưa trên lưu vực phân bố không đều theo thời gian, lượng mưa trong 4 tháng mùa mưa chiếm 80-85\% tổng lượng mưa năm, dẫn đến sự chênh lệch giữa lưu lượng dòng chảy lớn nhất và nhỏ nhất tại các tuyến đo là rất lớn, ví dụ tại An Khê là 69,9 lần, tại Củng Sơn là 25 lần [2]. Hậu quả là các thiên tai liên quan đến tài nguyên nước như hạn hán, lũ lụt, xâm nhập mặn, ô nhiễm nước xảy ra ở rất nhiều nơi trong lưu vực. Các nghiên cứu trước đây về $\mathrm{BĐKH}$ và tác động đến TNN ở LVSB ở Việt Nam đều được tiến hành theo cách tiếp cận từ trên xuống [1-4]. Như đã phân tích ở trên, kết quả của những nghiên cứu này đã gây nên những khó khăn cho nhà hoạch định chính sách trong việc ra quyết định các giải pháp thích ứng trên lưu vực.

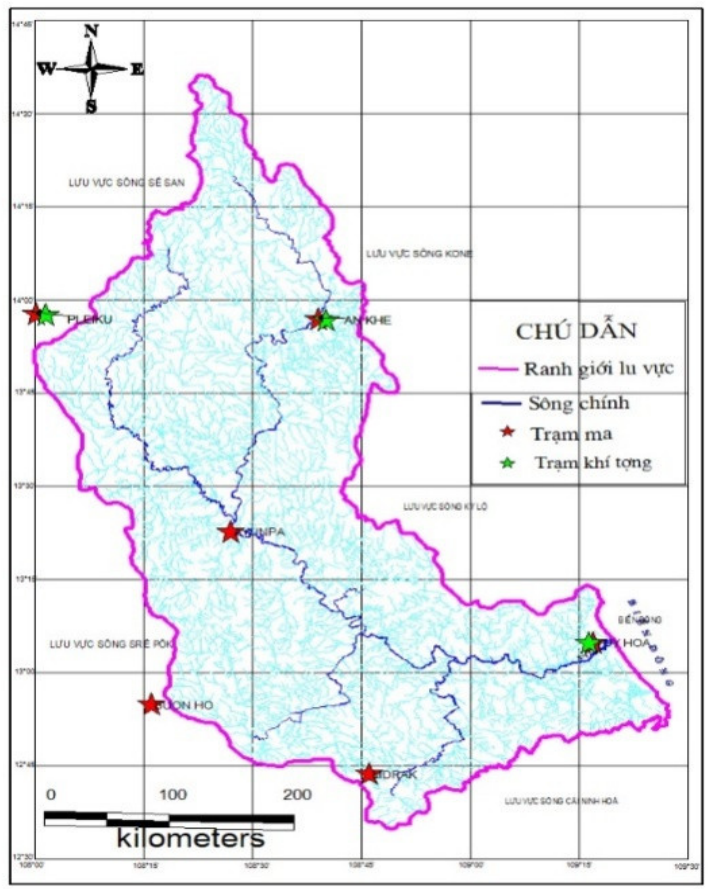

Hình 1. Bản đồ mạng lưới sông suối lưu vục sông $B a$

Bài báo này tập trung đánh giá tính không chắc chắn liên quan đến dự tính khí hậu, bao gồm kết quả dự tính từ GCMs; kỹ thuật chi tiết hóa và kỹ thuật hiệu chỉnh sai số hệ thống của các kết quả dự tính khí hậu ở LVSB, từ đó lựa chọn nhóm mô hình có tính không chắc chắn thấp nhất nhằm đưa ra dự tính khí hậu cho toàn LVSB trong tương lai. Kết quả của bài báo có ý nghĩa quan trọng trong việc làm tăng tính chắc chắn trong kết quả dự tính của các biến khí hậu làm đầu vào cho mô hình thủy văn và các mô hình hệ thống khác để đánh giá tác động của BĐKH đến hệ thống TNN trên lưu vực một cách hiệu quả.

2. Số liệu thu thập và phương pháp nghiên cứu

\subsection{Số liệu}

- Số liệu quan trắc: số liệu nhiệt độ và lượng mưa ngày trong giai đoạn 1986-2005 tại 3 trạm nhiệt độ (An Khê, Pleiku và Tuy Hòa) và 6 trạm mưa (An Khê, AuynPa, Pleiku, MDrak, Buôn Hồ và Tuy Hòa) được sử dụng làm cơ sở để đánh 
giá tính không chắc chắn của mô hình khí hậu thời kỳ nền.

- Số liệu mô hình khí hậu: tổng số 43 thành phần trong kết quả của 21 GCMs tương ứng với 4 kịch bản nồng độ khí nhà kính trong $\mathrm{AR} 5$ (RCP2.6, RCP4.5, RCP6.0, RCP8.5) của IPCC được sử dụng để dự tính khí hậu tương lai trên LVSB. Các kết quả này được nội suy từ các điểm lưới vào tọa độ của 3 trạm khí tượng và 6 trạm mưa bằng phương pháp nội suy song tuyến.

2.2 Phương pháp đánh giá tính không chắc chắn của kết quả dụ tính khí hậu tù̀ mô hình khí hậu

Có nhiều nghiên cứu đã định lượng tính không chắc chắn từ các kết quả dự tính khí hậu, trong đó áp dụng nhiều phương pháp với các bước thực hiện khác nhau $[11,17,26]$. Tuy nhiên nhìn chung, có 2 cách tiếp cận chính: (1) thông qua quá trình phân tích tính nhất quán giữa các kết quả mô phỏng của các thành phần mô hình khí hậu và (2) so sánh giữa các kết quả mô phỏng khí hậu trong quá khứ với dữ liệu thực đo $[11,20]$.

Trong bài báo này, tính không chắc chắn của các kết quả dự tính khí hậu từ các nhóm mô hình được đánh giá qua các chỉ số thống kê theo hai bước:

- Đánh giá kết quả mô phỏng khí hậu LVSB trong thời kỳ nền: Phân tích sai số trung bình (ME), sai số tuyệt đối trung bình (MAE) và so sánh biến trình các tháng trong năm giữa các kết quả mô phỏng với số liệu quan trắc tại trạm. Công thức tính ME và MAE như sau:

$$
\begin{aligned}
& M E=\frac{1}{N} \sum_{i=1}^{N}\left(F_{i}-O_{i}\right) \\
& M A E=\frac{1}{N} \sum_{i=1}^{N}\left|F_{i}-O_{i}\right|
\end{aligned}
$$

Trong đó $\mathrm{F}_{\mathrm{i}}$ và $\mathrm{O}_{\mathrm{i}}$ tương ứng là giá trị mô hình và giá trị quan trắc của một biến nào đó (nhiệt độ, lượng mưa); $\mathrm{N}$ là số lượng mẫu.

- Đánh giá kết quả dự tính khí hậu LVSB trong tương lai: Phân tích độ lệch chuẩn (SD) của kết quả dự tính khí hậu tại các bách phân vị khác nhau.
Giá trị của $\mathrm{ME}$ cho biết xu hướng lệch trung bình của giá trị dự báo so với giá trị quan trắc. Giá trị MAE biểu thị độ lệch trung bình của sai số mô hình nhưng không nói lên xu hướng lệch của giá trị dự báo và quan trắc. Độ lệch chuẩn SD cho thấy sự chênh lệch về giá trị của từng thời điểm đánh giá so với giá trị trung bình. Các sai số trên được áp dụng vào bài toán để đánh giá tính không chắc chắn của các nhóm mô hình khí hậu so với giá trị thực đo. Trong thời kỳ nền, nếu $M E$ và $M A E$ càng lớn thì tính không chắc chắn của mô hình càng cao, và ngược lại, nếu $\mathrm{ME}$ và MAE càng nhỏ thì tính không chắc chắn của mô hình càng thấp. Giá trị $\mathrm{SD}$ trong thời kỳ tương lai càng lớn thì tính không chắc chắn của mô hình càng cao và ngược lại. Bài báo so sánh các sai số này của 4 nhóm mô hình khí hậu và lựa chọn nhóm mô hình có tính không chắc chắn thấp nhất để dự tính cho mô hình khí hậu tương lai.

Các thời đoạn nghiên cứu gồm: 1986-2005 cho thời kỳ nền, 2016-2035 cho thời kỳ tương lai gần, 2046-2065 cho thời kỳ giữa thế kỷ và 2080-2099 cho cuối thế kỷ. Bốn nhóm mô hình khí hậu được sử dụng gồm:

1) GCMs: Nhóm này gồm tổng số 43 thành phần kết quả từ 20GCMs trong các kịch bản AR5 khác nhau (RCP2.6: 10 thành phần, RCP4.5: 20 thành phần, RCP6.0: 10 thành phần, RCP8.5: 10 thành phần);

2) RCMs: Nhóm này gồm tổng số 20 thành phần kết quả, có nguồn gốc từ một số GCMs được chi tiết hóa bằng RCMs (CCAM, clWRF và $\mathrm{PRECIS)} \mathrm{tương} \mathrm{ứng} \mathrm{với} \mathrm{các} \mathrm{kịch} \mathrm{bản} \mathrm{khác}$ nhau;

3) GCMs sau khi hiệu chỉnh sai số hệ thống (BC-GCMs): các kết quả từ nhóm 1 được hiệu chỉnh sai số hệ thống bằng phương pháp hiệu chỉnh phân vị (quantile-mapping) [6];

4) RCMs sau khi được hiệu chỉnh sai số hệ thống (BC-RCMs): các kết quả từ nhóm 2 được hiệu chỉnh sai số hệ thống bằng phương pháp hiệu chỉnh phân vị (quantile-mapping) [6].

Bảng 1 thể hiện danh sách các GCMs và RCMs và các thành phần mô hình khí hậu sử dụng trong nghiên cứu. 
Bảng 1. Danh sách các GCMs và RCMs được sủ dụng trong nghiên cứu

\begin{tabular}{|c|c|c|c|c|c|c|}
\hline \multicolumn{4}{|c|}{ GCMs } & \multicolumn{3}{|c|}{$\mathrm{RCMs}$} \\
\hline Mô hình & $\begin{array}{l}\text { Kích thước ô } \\
\text { lưới }(\mathrm{km})\end{array}$ & Mô hình & $\begin{array}{l}\text { Kích thước ô } \\
\text { lưới }(\mathrm{km})\end{array}$ & Mô hình & Thành phần & $\begin{array}{l}\text { Độ phân giải, } \\
\text { miền tính }(\mathrm{km})\end{array}$ \\
\hline ACCESS1-0 & $210 \times 130$ & HadCM3 & $410 \times 280$ & & ACCESS1-0; & $10 \mathrm{~km}, 5-30 \mathrm{~N}$ \\
\hline BCC-CSM1-1 & $310 \times 310$ & HadGEM2-AO & $210 \times 130$ & & CCSM4; & và $98-115 \mathrm{E}$ \\
\hline CanESM2 & $310 \times 310$ & HadGEM2-CC & $210 \times 130$ & CCAM & CNRM-CM5; & \\
\hline CCSM4 & $130 \times 100$ & INMCM4 & $220 \times 165$ & & GFDL-CM3; & \\
\hline CESM1-CAM5 & $130 \times 100$ & IPSL-CMSA-LR & $410 \times 210$ & & $\begin{array}{l}\text { MPI-ESM-LR; } \\
\text { NorESM1-M }\end{array}$ & \\
\hline CNRM-CM5 & $155 \times 155$ & MIROC5 & $155 \times 155$ & & & $30 \mathrm{~km}, 3,5-27 \mathrm{~N}$ \\
\hline $\begin{array}{l}\text { CSIRO-Mk3-6- } \\
0\end{array}$ & $210 \times 210$ & MPI-ESM-LR & $210 \times 210$ & clWRF & NorESM1-M & $\begin{array}{l}\text { và } 97,5-116 \mathrm{E} \\
25\end{array}$ \\
\hline GFDL-CM3 & $275 \times 220$ & MPI-ESM-MR & $210 \times 210$ & & CNRM CM5; & $25 \mathrm{~km}, 6,5-25 \mathrm{~N}$ \\
\hline GFDL-ESM2G & $275 \times 220$ & MRI-CGCM3 & $120 \times 120$ & PRECIS & GFDL-CM3; & và 99,5-115E \\
\hline GFDL-ESM2M & $275 \times 220$ & NorESM1-M & $275 \times 210$ & & HadGEM2-ES & \\
\hline
\end{tabular}

2.3 Phương pháp đánh giá sụ biến đổi của các yếu tố khí hậu tương lai

Mức độ biến đổi của các biến khí hậu được tính toán so với thời kỳ nền với công thức như sau:

- Đối với nhiệt độ trung bình:

$$
\Delta \mathrm{T}_{\text {future }}=\mathrm{T}_{\text {future }}^{*}-\overline{\mathrm{T}}_{1986-2005}^{*}
$$

- Đối với lượng mưa:

$$
\Delta P_{\text {future }}=\frac{P_{\text {future }}^{*}-\bar{P}_{1986-2005}^{*}}{\bar{P}_{1986-2005}^{*}} \times 100
$$

Trong đó $\Delta \mathrm{T}_{\text {future }}$ là biến đổi của nhiệt độ trong tương lai so với thời kỳ nền $\left({ }^{\circ} \mathrm{C}\right) ; \mathrm{T}_{\text {future }}^{*}$ là giá trị nhiệt độ trong tương lai mô phỏng từ mô hình $\left({ }^{\circ} \mathrm{C}\right) ; \overline{\mathrm{T}}_{1986-2005}$ là nhiệt độ trung bình của thời kỳ nền $(1986-2005)\left({ }^{\circ} \mathrm{C}\right) ; \Delta \mathrm{P}_{\text {future }}$ là biến đổi của lượng mưa trong tương lai so với thời kỳ nền $(\%)$; $\mathrm{P}_{\text {future }}^{*}$ là lượng mưa trong tương lai mô phỏng từ mô hình (mm).

$\mathrm{P}_{1986-2005}^{*}$ là lượng mưa trung bình của thời kỳ

Bảng 2. Sai số tuyệt đối và sai số tuyệt đối trung bình của nhiệt độ thời kỳ nền trong mô hình khí

\begin{tabular}{|c|c|c|c|c|c|c|c|c|c|c|c|c|}
\hline \multirow[b]{2}{*}{$\begin{array}{l}\text { Mô } \\
\text { hình }\end{array}$} & \multicolumn{3}{|c|}{ GCMs } & \multicolumn{3}{|c|}{$\mathrm{RCMs}$} & \multicolumn{3}{|c|}{ BC-GCMs } & \multicolumn{3}{|c|}{$\mathrm{BC}-\mathrm{RCMs}$} \\
\hline & $\begin{array}{l}\text { Mùa } \\
\text { mưa }\end{array}$ & $\begin{array}{l}\text { Mùa } \\
\text { khô }\end{array}$ & $\begin{array}{c}\text { Cả } \\
\text { năm }\end{array}$ & $\begin{array}{l}\text { Mùa } \\
\text { mưa }\end{array}$ & $\begin{array}{l}\text { Mùa } \\
\text { khô }\end{array}$ & $\begin{array}{c}\text { Cả } \\
\text { năm }\end{array}$ & $\begin{array}{l}\text { Mùa } \\
\text { mưa }\end{array}$ & $\begin{array}{l}\text { Mùa } \\
\text { khô }\end{array}$ & $\begin{array}{c}\text { Cả } \\
\text { năm }\end{array}$ & $\begin{array}{l}\text { Mùa } \\
\text { mưa }\end{array}$ & $\begin{array}{l}\text { Mùa } \\
\text { khô }\end{array}$ & $\begin{array}{c}\text { Cả } \\
\text { năm }\end{array}$ \\
\hline $\mathrm{ME}$ & $-24,0$ & 42,7 & $-8,5$ & $-3,8$ & 85,7 & 14,4 & 1,6 & 6,0 & 2,6 & 1,4 & 3,9 & 1,5 \\
\hline MAE & 39,3 & 79,4 & 34,1 & 37,1 & 116,6 & 39,3 & 31,5 & 55,0 & 27,2 & 31,2 & 49,6 & 25,7 \\
\hline
\end{tabular}
hậu so với số liệu quan trắc

Đối với các biến lượng mưa: Bảng 3 cho thấy các giá trị sai số của mô hình GCMs và RCMs có sự khác nhau, với $\mathrm{ME}(\mathrm{GCMs})=(-8,5)$ và $\mathrm{ME}$ nền (1986-2005) (mm)

\section{Kết quả}

3.1 Đánh giá tính không chắc chắn của các kết quả dụ tính khí hậu ở lưu vục sông Ba tù̀ mô hình khí hậu

3.1.1 Tính không chắc chắn của mô hình khí hậu thời kỳ nền

Đối với các biến nhiệt độ: Tại tất cả các trạm trên LVSB, kết quả mô phỏng của GCMs có xu hướng lớn hơn số liệu thực đo, trong khi kết quả từ RCMs có xu hướng nhỏ hơn (trung bình trên toàn lưu vực, ME của GCMs là 0,23 và $R C M s$ là $-0,65)$. Chỉ số MAE của kết quả GCMs lớn hơn so với kết quả của RCMs (trung bình trên toàn lưu vực, MAE của GCMs là 1,7 so với 0,84 của RCMs). Sau khi áp dụng phương pháp hiệu chỉnh sai số, các kết quả của mô hình GCMs và RCMs tốt hơn nhiều. Cụ thể, giá trị ME tại tất cả các trạm trong lưu vực bằng 0,02 đối với $\mathrm{BC}$ GCMs và 0,0 đối với $\mathrm{BC}-\mathrm{RCMs}$.
$(\mathrm{RCMs})=14,4$. Đặc biệt vào mùa khô, kết quả mô hình so với kết quả thực đo có sự sai lệch đáng kể (ME trong mùa khô của GCMs là 42,7; 
của RCMs là 85,7). Sau khi hiệu chỉnh sai số, sai số trung bình của GCMs và RCMs đều giảm đáng kể, kết quả của $\mathrm{ME}(\mathrm{BC}-\mathrm{RCMs})=1,5$ tốt hơn so với $\mathrm{ME}(\mathrm{BC}-\mathrm{GCMs})=2,6)$. Tuy nhiên, sai số tuyệt đối trung bình cải thiện không đáng kể (MAE hàng năm của $\mathrm{BC}-\mathrm{GCMs}$ và $\mathrm{BC}$ RCMs lần lượt là 27,2 và 25,7$)$. Với tất cả các nhóm mô hình, giá trị MAE trong mùa khô khá lớn so với mùa mưa.

So sánh biến trình lượng mưa theo các tháng trong năm giữa mô phỏng và thực đo (Hình 2) trong giai đoạn thời kỳ nền cho thấy kết quả mô phỏng của nhóm mô hình khí hậu đã hiệu chỉnh sai số hệ thống là tốt hơn hẳn so với nhóm chưa hiệu chỉnh sai số hệ thống, đối với cả GCMs và RCMs, đặc biệt vào mùa mưa.

Bảng 3. Sai số trung bình và sai số tuyệt đối trung bình của lượng mưa mô phỏng của các nhóm mô hình khi hậu so với số liệu quan trắc

\begin{tabular}{|c|c|c|c|c|c|c|c|c|c|c|c|c|}
\hline \multirow{2}{*}{$\begin{array}{l}\text { Mô } \\
\text { hình }\end{array}$} & \multicolumn{3}{|c|}{ GCMs } & \multicolumn{3}{|c|}{ RCMs } & \multicolumn{3}{|c|}{ BC-GCMs } & \multicolumn{3}{|c|}{ BC-RCMs } \\
\hline & $\begin{array}{l}\text { Mùa } \\
\text { mưa }\end{array}$ & $\begin{array}{l}\text { Mùa } \\
\text { khô }\end{array}$ & $\begin{array}{c}\text { Cả } \\
\text { năm }\end{array}$ & $\begin{array}{l}\text { Mùa } \\
\text { mưa }\end{array}$ & $\begin{array}{l}\text { Mùa } \\
\text { khô }\end{array}$ & $\begin{array}{c}\text { Cả } \\
\text { năm }\end{array}$ & $\begin{array}{l}\text { Mùa } \\
\text { mưa }\end{array}$ & $\begin{array}{l}\text { Mùa } \\
\text { khô }\end{array}$ & $\begin{array}{c}\text { Cả } \\
\text { năm }\end{array}$ & $\begin{array}{l}\text { Mùa } \\
\text { mưa }\end{array}$ & $\begin{array}{l}\text { Mùa } \\
\text { khô }\end{array}$ & $\begin{array}{c}\text { Cả } \\
\text { năm }\end{array}$ \\
\hline $\mathrm{ME}$ & $-24,0$ & 42,7 & $-8,5$ & $-3,8$ & 85,7 & 14,4 & 1,6 & 6,0 & 2,6 & 1,4 & 3,9 & 1,5 \\
\hline MAE & 39,3 & 79,4 & 34,1 & 37,1 & 116,6 & 39,3 & 31,5 & 55,0 & 27,2 & 31,2 & 49,6 & 25,7 \\
\hline
\end{tabular}

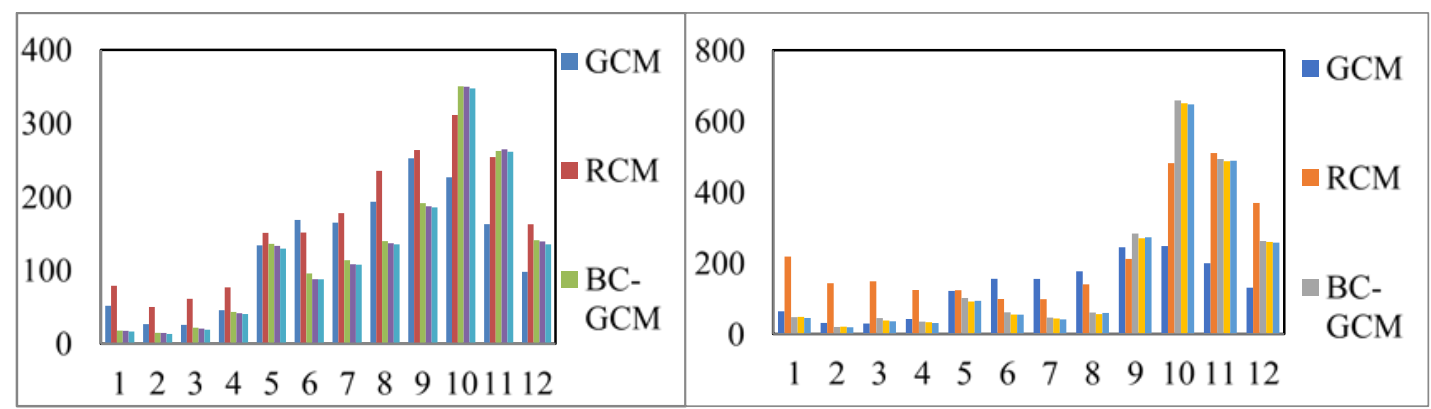

Hình 2. Biến trình lương mưa theo các tháng trong năm giữa mô phỏng và quan trắc ở trạm An Khê và Tuy Hòa

Như vậy, trong kết quả mô phỏng khí hậu ở LVSB ở thời kỳ nền, nhóm mô hình đã được hiệu chỉnh sai số hệ thống (đối với cả GCMs và $\mathrm{RCMs}$ ) có tính không chắc chắn thấp hơn hẳn so với nhóm mô hình chưa được hiệu chỉnh sai số. Trong khi tính không chắc chắn giữa hai nhóm GCMs và RCMs (đối với cả hiệu chỉnh và chưa hiệu chỉnh) không có sự khác biệt rõ rệt. Do đó, trong bước tiếp theo của nghiên cứu này, bài báo chỉ tập trung so sánh tính không chắc chắn của các kết quả dự tính ở các thời kỳ tương lai của hai nhóm $\mathrm{BC}-\mathrm{GCMs}$ và $\mathrm{BC}-\mathrm{RCMs}$ mà bỏ qua các kết quả không được hiệu chỉnh sai số hệ thống.
3.1.2 Tính không chắc chắn trong các dụ tính khí hậu tuoong lai của $B C-G C M s$ và $B C-R C M s$

Đối với các biến nhiệt độ: Nhìn chung, trong tất cả các giai đoạn tương lai, tại tất cả các phân vị, độ lệch chuẩn của $\mathrm{BC}-\mathrm{GCM}$ k khá lớn so với BC-RCMs (Bảng 4). Cụ thể, trong giai đoạn 2016-2035, giá trị độ lệch chuẩn của BC-GCMs ở phân vị thứ 10 và 90 lần lượt là 0,45 và 0,51 , trong khi các chỉ số này của $\mathrm{BC}-\mathrm{RCMs}$ là 0,23 và 0,38 . Càng đến cuối thế kỷ, giá trị độ lệch chuẩn càng cao đối với cả $\mathrm{BC}-\mathrm{GCMs}$ và $\mathrm{BC}$ RCMs.

Bảng 4. Độ lệch chuẩn biến nhiệt độ của $B C-G C M$ và $B C-R C M$

\begin{tabular}{ccccccccc}
\hline \multirow{2}{*}{ Phân vị } & \multicolumn{4}{c}{ BC-GCMs } & \multicolumn{4}{c}{ BC-RCMs } \\
\cline { 2 - 9 } Giai đoận & $10^{\text {th }}$ & $50^{\text {th }}$ & $90^{\text {th }}$ & TB & $10^{\text {th }}$ & $50^{\text {th }}$ & $90^{\text {th }}$ & TB \\
\hline $2016-2035$ & 0,45 & 0,48 & 0,51 & 0,46 & 0,23 & 0,28 & 0,38 & 0,28 \\
$2046-2065$ & 0,65 & 0,71 & 0,75 & 0,69 & 0,46 & 0,55 & 0,60 & 0,54 \\
$2080-2099$ & 1,07 & 1,12 & 1,16 & 1,12 & 0,97 & 1,03 & 1,06 & 1,01 \\
\hline
\end{tabular}



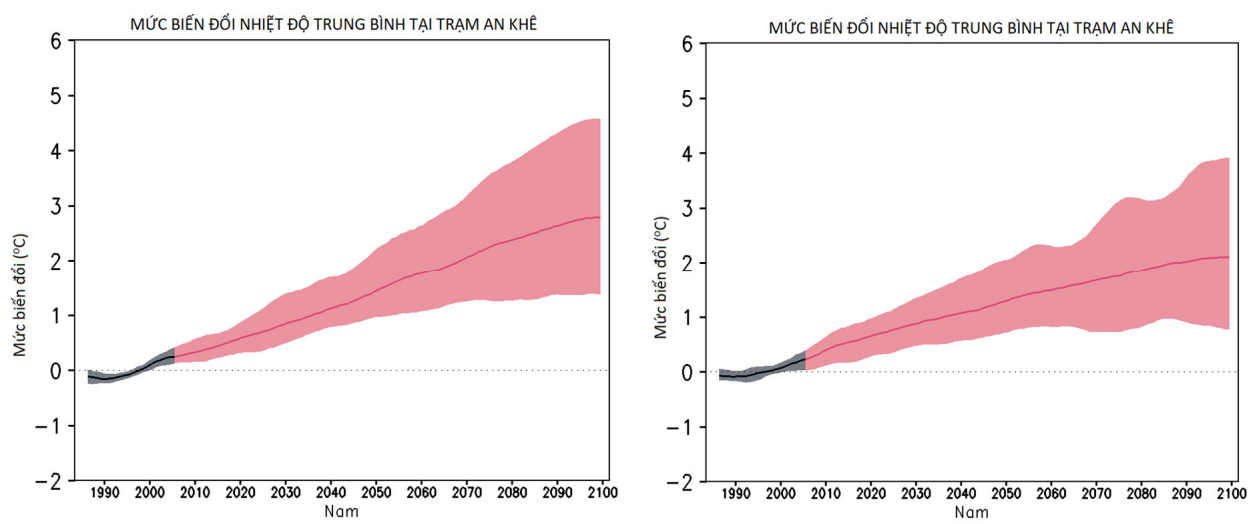

Hình 3. Phạm vi biến thiên sụ thay đổi nhiệt độ trong thế kỷ 21 của BC-GCMs (trái) và BC-RCMs (phải) tại trạm An Khê

Hình 3 cho thấy phạm vi biến thiên nhiệt độ của $\mathrm{BC}-\mathrm{GCMs}$ và $\mathrm{BC}-\mathrm{RCMs}$ đều tăng dần vào cuối thế kỷ. Vào năm 2100 , phạm vi này lên đến $3-4^{\circ} \mathrm{C}$.

Đối với các biến lượng mưa: Nhìn chung, tính không chắc chắn của $\mathrm{BC}-\mathrm{GCMs}$ ở tất cả các phân vị đều ở mức cao (Bảng 5). Trong giai đoạn 2016-2035, giá trị độ lệch chuẩn lần lượt là 449,89 và $1.167,27$ ở phân vị thứ 10 và 90 . Đến cuối thế kỷ, các giá trị này lần lượt là 484,81 và $1.272,78$ cho thấy sự tăng nhẹ của các kết quả
$\mathrm{BC}-\mathrm{GCMs}$ trong suốt thế kỷ. Đối với BC-RCMs, kết quả được cải thiện đáng kể, nhưng vẫn ở mức cao. Đặc biệt trong giai đoạn tương lai gần, giá trị độ lệch chuẩn ở phân vị thứ 10 và 90 giảm xuống còn 171,88 và 316,22 . Đến cuối thế kỷ, các giá trị này lần lượt là 247,07 và 482,97 . Hình 4 cho thấy, phạm vi biến thiên sự thay đổi lượng mưa của $\mathrm{BC}-\mathrm{GCMs}$ lớn nhất vào giai đoạn giữa thế kỷ và giảm dần vào cuối thế kỷ. Trong khi đó, phạm vi biến thiên của BC-RCMs càng về cuối thế kỷ càng tăng.

Bảng 5. Độ lệch chuẩn biến lượng mưa của BC-GCM và BC-RCM

\begin{tabular}{ccccccccc}
\hline \multirow{2}{*}{ Phân vi } & \multicolumn{4}{c}{ BC-GCMs } \\
\cline { 2 - 9 } Giai đoạt & $10^{\text {th }}$ & $50^{\text {th }}$ & $90^{\text {th }}$ & TB & $10^{\text {th }}$ & $50^{\text {th }}$ & $90^{\text {th }}$ & TB \\
\hline $2016-2035$ & 449,89 & 613,75 & 1167,27 & 726,06 & 171,88 & 219,94 & 316,22 & 198,38 \\
$2046-2065$ & 474,61 & 644,13 & 1492,78 & 725,68 & 193,12 & 257,83 & 392,87 & 256,61 \\
$2080-2099$ & 484,81 & 679,20 & 1272,78 & 727,47 & 247,07 & 320,10 & 482,97 & 332,05 \\
\hline
\end{tabular}
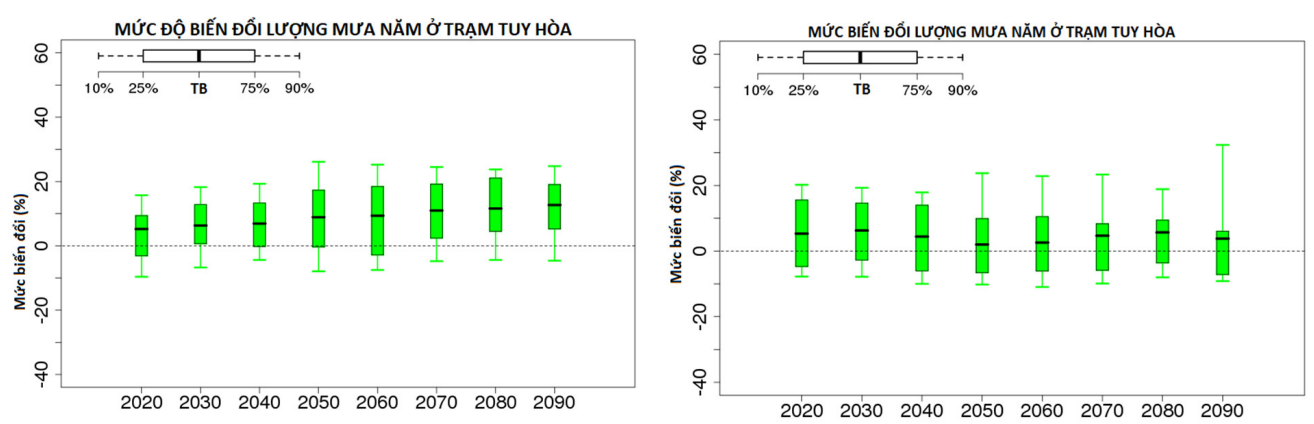

Hình 4. Phạm vi biến thiên sụ thay đổi lương mua trong thế kỷ 21 của BC-GCMs (trái) và BCRCMs (phải) tại trạm Tuy Hòa

Như vậy, kết quả dự tính khí hậu từ các thành phần $\mathrm{BC}-\mathrm{GCM}$ s có tính không chắc chắn lớn hơn so với các $\mathrm{BC}-\mathrm{RCMs}$. Phần tiếp theo sẽ sử dụng kết quả từ $\mathrm{BC}-\mathrm{RCMs}$ để dự tính khí hậu tương lai ở LVSB.

\subsection{Kết quả dụ tính khí hậu tương lai ở lưu vục sông $B a$}

Như đã phân tích ở trên, một trong những 


\section{BÀI BÁO KHOA HỌC}

nguồn gây nên tính không chắc chắn trong kết quả dự tính khí hậu theo cách tiếp cận top-down chính là xem xét các kịch bản phát triển KT-XH hoặc kịch bản phát thải KNK khác nhau [12,24]. Vì vậy, nghiên cứu này không dự tính điều kiện khí hậu tương lai ở LVSB theo các kịch bản này, mà xem xét tất cả các khả năng có thể xảy ra của khí hậu tương lai, trong mọi điều kiện phát triển $\mathrm{KT}-\mathrm{XH}$ và phát thải $\mathrm{KNK}$ trên lưu vực, với giả thiết mỗi kết quả dự tính khí hậu từ mô hình ứng với mỗi kịch bản được cho là 1 khả năng có thể xảy ra của khí hậu tương lai.

\subsubsection{Sự biến đổi của yếu tố nhiệt độ}

Mức tăng nhiệt độ trung bình năm tại trạm Tuy Hòa cao nhất so với 2 trạm An Khê và Pleiku (Hình 5). Cụ thể, mức tăng trung bình năm $3,8^{\circ} \mathrm{C}$ ở giai đoạn tương lai gần; $4,4^{\circ} \mathrm{C}$ ở giữa thế kỷ và $4,8^{\circ} \mathrm{C}$ ở cuối thế kỷ. Trong khi đó, tại các trạm An Khê và Pleiku có mức tăng nhiệt độ không đáng kể. Nhìn chung có thể thấy mức tăng nhiệt độ tại các trạm trên LVSB càng tăng dần vào giai đoạn cuối thế kỷ.

Trên LVSB, nhiệt độ không khí có sự phân hóa theo độ cao địa hình và các mùa trong năm. Ở phần thượng nguồn của lưu vực, nhiệt độ trung bình là $23^{\circ} \mathrm{C}$, trong khi ở khu vực hạ du gần biển, nhiệt độ trung bình hàng năm là khoảng $27^{\circ} \mathrm{C}$. Hình 6 cho thấy mức tăng nhiệt độ trung bình năm trên LVSB có sự phân bố theo không gian, càng xuống hạ lưu lưu vực thì mức tăng nhiệt độ càng cao. Ngoài ra, khu vực ven biển có nền nhiệt độ cao hơn nên có xu hướng mức tăng nhiệt độ cao hơn so với khu vực thượng nguồn có nền nhiệt độ thấp. Điều đó cho thấy, nền nhiệt độ trên LVSB trong tương lai có sự chênh lệch rõ rệt giữa các vùng theo vị trí, độ cao địa hình, gây ra những hậu quả về biến đỗi khí hậu nghiêm trọng hơn ở vùng có mức tăng nhiệt độ cao.

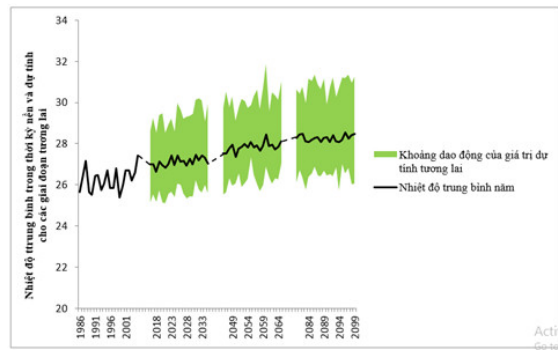

(a)

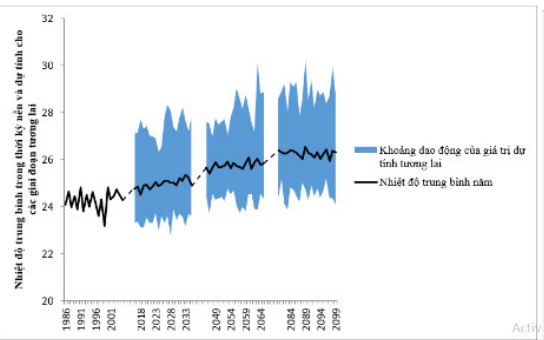

(b)

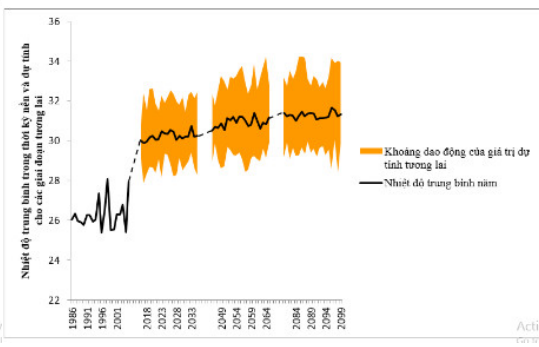

(c)

Hình 5. Khoảng dao động tương lai của nhiệt độ trung bình năm tại 3 trạm (a) An Khê (b) Pleiku (c) Tuy Hòa

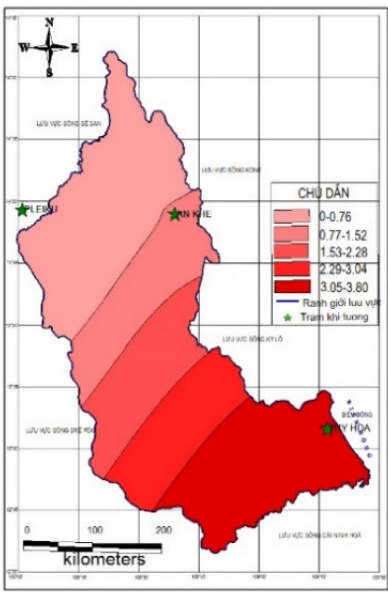

(a)

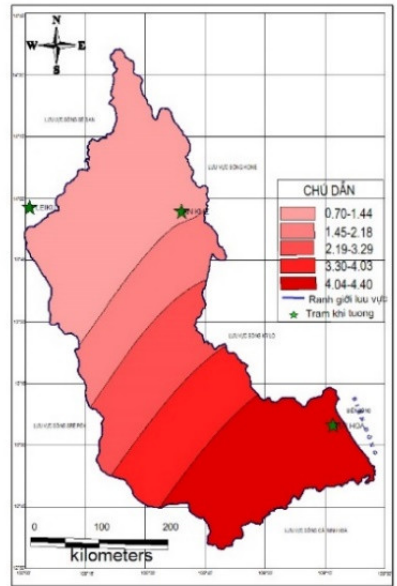

(b)

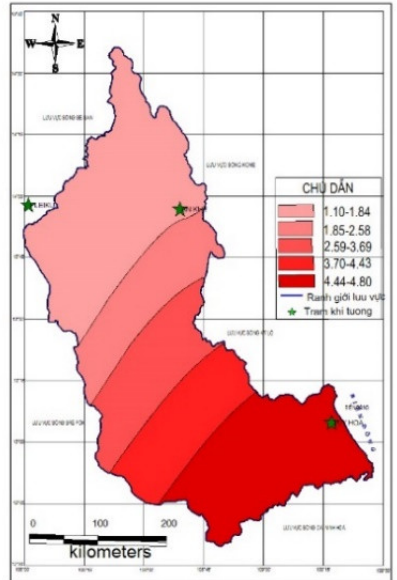

(c)

Hình 6. Bản đồ thể hiện mức tăng nhiệt độ trung bình năm thời kỳ (a) TLG(b) GTK(c) CTK 


\subsubsection{Sự biến đổi của yếu tố lượng mưa}

Nhìn chung, mức tăng lượng mưa trung bình năm trong tất cả giai đoạn tương lai đều có xu hướng tăng so với thời kỳ nền tại tất cả các trạm, mức tăng nhiều hơn vào giai đoạn giữa thế kỷ so với cuối thế kỷ (Hình 7). Cụ thể, trạm An Khê có mức tăng lượng mưa trung bình năm vào thời kỳ tương lai gần là $14,0 \% ; 18,0 \%$ vào giữa thế kỷ và $12,3 \%$ vào cuối thế kỷ. Trong khi đó, trạm Tuy Hòa có mức tăng lượng mưa trung bình năm thấp nhất so với các trạm trên lưu vực, cụ thể, mức tăng lượng mưa trung bình năm $8,3 \%$ vào tương lai gần; $8,7 \%$ vào giữa thế kỷ và $6,9 \%$ vào cuối thế kỷ. Trong mỗi giai đoạn tương lai, mức tăng lượng mưa vào mùa khô $(7,6 \%-31,1 \%)$ đều cao hơn so với mức tăng lượng mưa vào mùa mưa $(5,1 \%-14,5 \%)$ và có mức tăng cao nhất vào giai đoạn giữa thế kỷ (Hình 8, 9).

Bên cạnh đó, lượng mưa trên LVSB có sự phân bố không đều theo không gian và thời gian dẫn đến sự biến đổi lượng mưa tại các vùng có sự khác biệt. Vùng thượng lưu có mức tăng lượng mưa trung bình năm cao hơn vùng hạ lưu ven biển trong giai đoạn tương lai gần và giữa thế kỷ; vùng phía tây lưu vực có mức tăng lượng mưa trung bình năm cao vào giai đoạn cuối thế kỷ. Ví dụ, vùng Đông Trường Sơn có mùa khô kéo dài từ tháng I đến tháng VIII, lượng mưa không nhiều nên có mức tăng lượng mưa trong tương lai thấp hơn so với vùng Tây Trường Sơn và vùng Trung gian, gây hậu quả hạn hán, suy giảm dòng chảy vào mùa kiệt khiến cho măn xâm nhập sâu vào trong sông, dẫn đến tỉnh trạng thiếu nước càng nghiêm trọng.

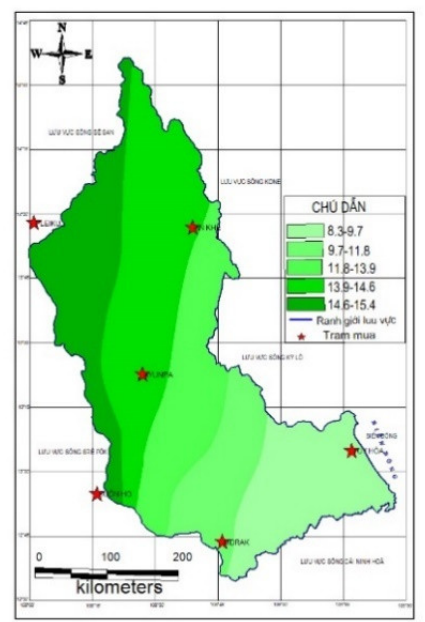

(a)

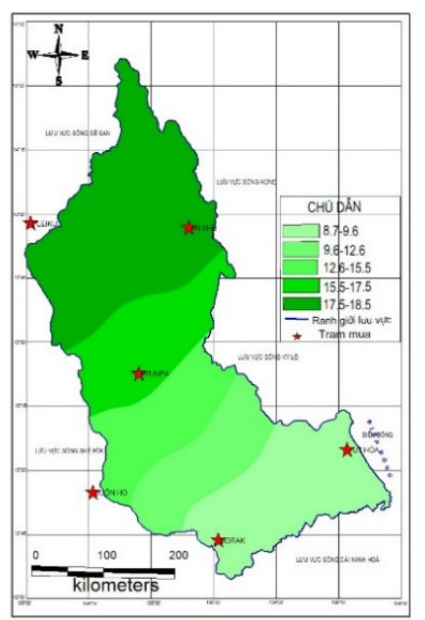

(b)

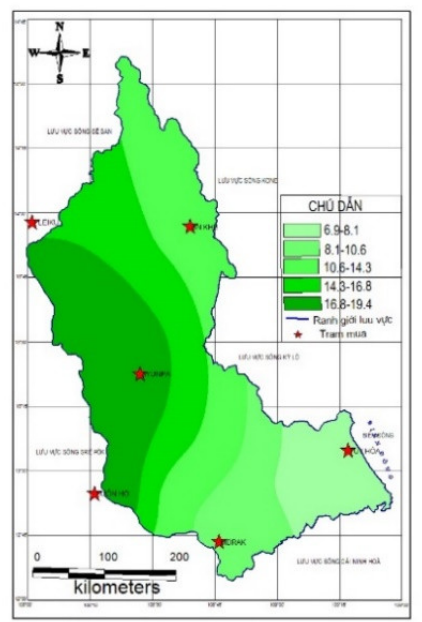

(c)

Hình 7. Bản đồ thể hiện mức tăng lượng mưa trung bình năm thời kỳ (a) TLG (b) GTK (c) CTK

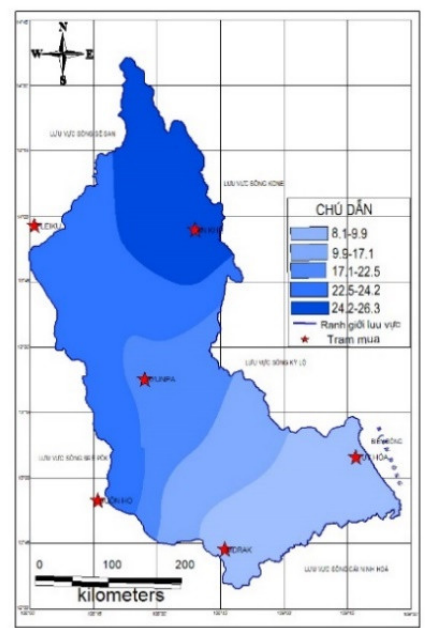

(a)

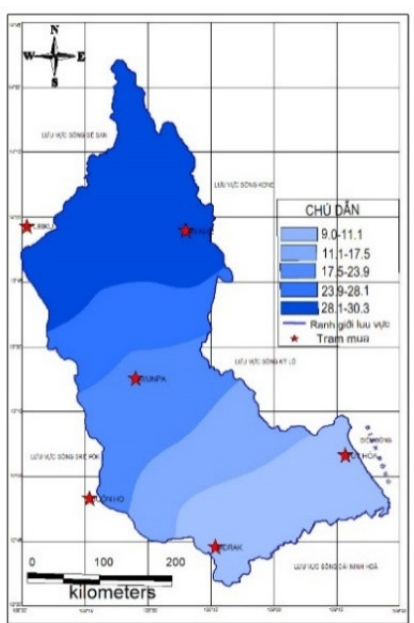

(b)

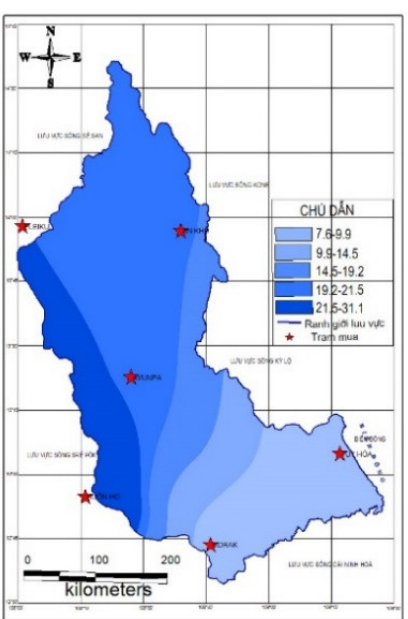

(c)

Hình 8. Bản đồ thể hiện mức tăng lượng mưa trung bình mùa khô thời kỳ

(a) TLG (b) GTK (c) CTK 


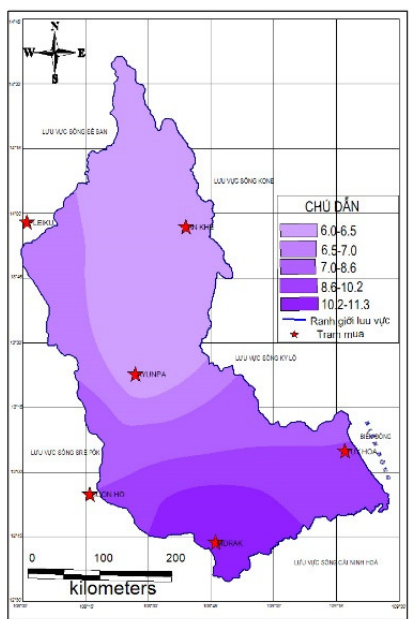

(a)

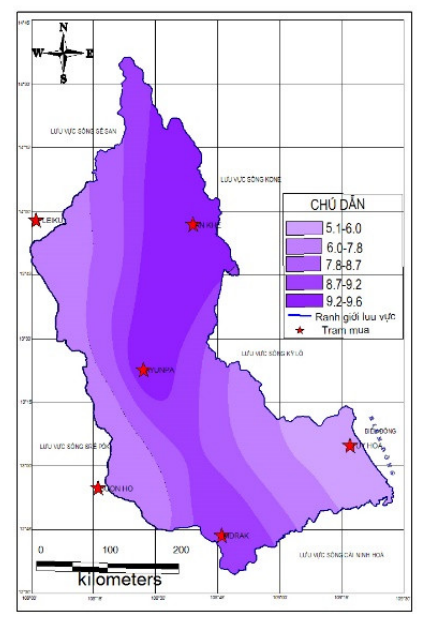

(b)

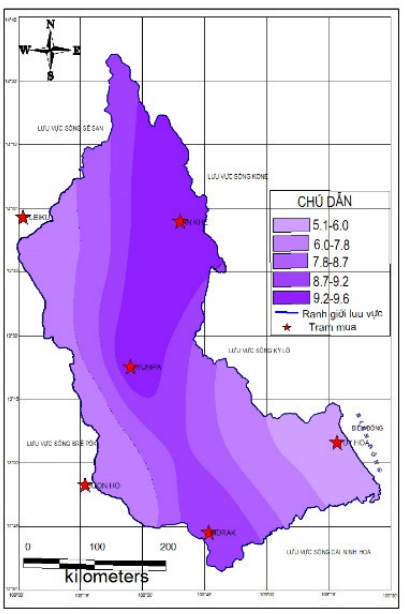

(c)

Hình 9. Bản đồ thể hiện mức tăng lương mua trung bình mùa khô thời kỳ

(a) TLG (b) GTK (c) CTK

\section{Kết luận}

Trong bài báo này, các tác giả đã đánh giá tính không chắc của 4 nhóm mô hình khí hậu ở LVSB từ kết quả mô phỏng thời kỳ nền và dự tính thời kỳ tương lai, từ đó lựa chọn nhóm mô hình có tính không chắc chắn thấp nhất để đưa ra dự tính khí hậu cho toàn LVSB trong tương lai. Kết quả đánh giá tính không chắc chắn của mô hình khí hậu trong thời kỳ nền cho thấy kỹ thuật hiệu chỉnh sai số hệ thống có hiệu quả hơn kỹ thuật chi tiết hóa động lực trong việc nắm bắt điều kiện khí hậu thực tế tại lưu vực. Trong kết quả dự tính tương lai, kỹ thuật chi tiết hóa động lực có biểu hiện tốt hơn trong việc hạn chế tính không chắc chắn trong dự tính điều kiện kết quả tương lai trên lưu vực, cụ thể nhóm mô hình $\mathrm{BC}$ $\mathrm{RCMs}$ cho có độ lệch chuẩn thấp hơn hẳn so với nhóm mô hình $\mathrm{BC}-\mathrm{GCMs}$.
Theo kết quả dự tính điều kiện khí hậu tương lai ở LVSB theo kết quả BC-RCMs, đối với các biến nhiệt độ, mức tăng nhiệt độ dao động từ 0 $4,8^{\circ} \mathrm{C}$ trong các giai đoạn tương lai. Vùng hạ lưu ven biển có nền nhiệt độ cao nên có mức tăng nhiệt độ trung bình năm cao hơn vùng thượng lưu lưu vực trong các giai đoạn tương lai. Đối với các biến lượng mưa, trong tương lai mức tăng lượng mưa trung bình năm tại các trạm có sự khác biệt. Vùng thượng lưu có mức tăng lượng mưa trung bình năm cao hơn vùng hạ lưu ven biển trong giai đoạn tương lai gần và giữa thế kỷ; vùng phía tây lưu vực có mức tăng lượng mưa trung bình năm cao vào giai đoạn cuối thế kỷ. Trong mùa mưa, mức tăng lượng mưa thấp hơn so với mùa khô (mùa mưa là $5,1 \%-14,5 \%$, mùa khô là 7,6\%-31,1\%) và có mức tăng cao nhất vào giai đoạn giữa thế kỷ.

Lời cám ơn: Kết quả của bài báo là một phần kết quả nghiên cứu của NCS Vũ Thị Vân Anh với đề tài "Cách tiếp cận kết hợp giũua dụ tính khi hậu và ngữ̛ng hoạt động của hệ thống trong đánh giá tác động của BĐKH đến tài nguyên nước trên lưu vực sông - Áp dụng cho lưu vực sông Ba".

\section{Tài liệu tham khảo}

1. Huỳnh Thị Lan Hương (2013), Kết quả nghiên cưu tác động của Biến đổi khi hậu đến dòng chảy Lư vực sông Ba. Tạp chí Khoa học và công nghệ thủy lợi, 13, 71-79.

2. Lê Đức Thường (2012), Các vấn đề tồn tại trong khai thác, sủ dụng, quản lý, quy hoạch và phát triển tài nguyên nước lưu vực sông Ba. Tạp chí khoa học, Đại học Huế, 5, 177-184.

3. Trần Thanh Xuân, Trần Thục, Hoàng Minh Tuyển (2011), Tác động của Biến đổi khí hậu đến tài nguyên nước Việt Nam. NXB Khoa học Kỹ thuật, Hà Nội, 304 trang. 
4. Viện Quy hoạch Thủy lợi (2017), Điều chỉnh quy hoạch thủy lợi lưu vục sông Ba và vùng phu cận giai đoạn 2025, tầm nhìn 2035, 314 trang.

5. Bastola, S., Murphy, C., Sweeney, J., (2011), The role of hydrological modelling uncertainties in climate change impact assessments of Irish river catchments. Adv. Water Resour. ADV WATER RESOUR, 34, 562-576.

6. Brekke, L.D., Kiang, J.E., Olsen, J.R., Pulwarty, R.S., Raff, D.A., Turnipseed, D.P., Webb, R.S., White, K.D., (2009), Climate change and water resources management. A federal perspective, U.S, Geological Survey Circular, 1331, 65.

7. Brown, C., Ghile, Y., Laverty, M., Li, K., (2012), Decision scaling: Linking bottom-up vulnerability analysis with climate projections in the water sector. Water Resour. Res., 48 (9), 1-12.

8. Brown, C., Werick, W., Leger, W., Fay, D., (2011), A Decision-Analytic Approach to Managing Climate Risks: Application to the Upper Great Lakes. J. Am. Water Resour. Assoc., 47( 3), 524-534.

9. Carter, K., T.R. and Mäkinen, (2011), Approaches to climate change impact, adaptation and vulnerability assessment: towards a classification framework to serve decision-making, Helsinki, Finland.

10. Christensen, N., Lettenmaier, D. (2007), A Multimodel Ensemble Approach to Assessment of Climate Change Impacts on the Hydrology and Water Resources of the Colorado River Basin. Hydrol. Earth Syst. Sci., 11, 1417-1434.

11. Dessai, S., Lu, X., Hulme, M., (2005), Limited sensitivity analysis of regional climate change probabilities for the 21st century. J. Geophys. Res., 110 (D19), D19108.

12. García, L.E., Matthews, J., Rodriguez, D.J, Wijnen, M., DiFrancesco, K.N., Ray, P., (2014), A Bottom-up Approach to Climate Adaptation for Water Resources Management BEYOND DOWNSCALING.

13. Graham, L.P., Andréasson, J., Carlsson, B., (2007), Assessing climate change impacts on hydrology from an ensemble of regional climate models, model scales and linking methods - a case study on the Lule River basin. Clim. Change, 81, 293-307.

14. Hamlet, A., Lettenmaier, D. (2007), Effects of Climate Change on Hydrology and Water Resources in the Columbia River Basin. JAWRA J. Am. Water Resour. Assoc., 35, 1597-1623.

15. Hallegatte, S., A. Shah, A., Lempert, R., Brown, C., Gill, S., (2012), Investment Decision Making under Deep Uncertainty - Application to Climate Change. Policy Res. Work. Pap., 6193 (9).

16. Kay, A., Davies, H., Bell, V., Jones, R., (2008), Comparison of Uncertainty Sources for Climate Change Impacts: Flood Frequency in England. Clim. Change, 92, 41-63.

17. Li, G., Zhang, X., Zwiers, F., Wen, Q.H., (2012), Quantification of uncertainty in high-resolution temperature scenarios for North America. J. Clim., 25 (9), 3373-3389.

18. Maurer, E., Hidalgo, H., (2008), Utility of daily vs. monthly large-scale climate data: An intercomparison of two statistical downscaling methods. Hydrol. Earth Syst. Sci. 12, 551-563.

19. Minville, M., Brissette, F., Leconte, R., (2008), Uncertainty of the Impact of Climate Change on the Hydrology of a Nordic Watershed. J. Hydrol., 358, 70-83.

20. Raisanen, J., (2007), How reliable are climate models? Tellus A 59 (1), 2-29.

21. Rowell, D., (2006), A Demonstration of the Uncertainty in Projections of UK Climate Change Resulting from Regional Model Formulation. Clim. Change, 79, 243-257.

22. Vano, J., Voisin, N., Cuo, L., Hamlet, A., (2010), Climate change impacts on water management in the Puget Sound region, Washington State, USA. Clim. Change, 102, 261-286.

23. Vicuña, S., Dracup, J.A., Lund, J., Dale, L., Maurer, E., (2010), Basin-Scale Water System Op- 


\title{
BÀI BÁO KHOA HỌC
}

erations With Uncertain Future Climate Conditions: Methodology and Case Studies. Water Resour. Res., 46, W04505, doi:10.1029/2009WR007838.

24. Wilby, S., Dessai, R.L., (2010), Robust adaptation to climate change. Weather, 65(7), 180185.

25. Wiley, M., Palmer, R., (2008), Estimating the Impacts and Uncertainty of Climate Change on a Municipal Water Supply System. J. Water Resour. Plan. Manag. - J WATER RESOUR PLAN MAN-ASCE, 134.

26. Woldemeskel, F.M., Sharma, A., Sivakumar, B., Mehrotra, R., (2014), A framework to quantify GCM uncertainties for use in impact assessment studies. J. Hydrol, 519 (PB), 1453-1465.

\section{FUTURE CLIMATE PROJECTION OF BA RIVER BASIN IN THE UNCERTAIN CONTEXT OF CLIMATE MODELS Phan Thi Thuy Duong ${ }^{1}$, Vu Thi Van Anh ${ }^{1,2}$, Nguyen Thi Tuyet ${ }^{1}$ \\ ${ }^{1}$ Hochiminh University of Natural Resources and Environment \\ ${ }^{2}$ Hochiminh University of Technology}

\begin{abstract}
This investigation evaluates uncertainties of baseline simulations and future projections in the Ba river basin (BRB) of 4 groups of climate models: Global Climate Models (GCMs), Regional Climate Models (RCMs), bias-corrected GCMs, bias-corrected RCMs. The methods used for evaluating uncertainties in baseline are analyzing Mean errors (ME), Mean absolute errors (MAE). The annual variations were compared between simulation data with monitoring data at 3 temperature stations and 6 precipitation stations. The estimation the future baseline climate by analyzing the standard deviation (SD) of climate estimation results at different percentiles. Since then, the study chooses the model group which has the lowest uncertain values to project future climate condition in the BRB in future. The results in baseline period show that the bias-corrected climate model group gives significant lower uncertainties than the unbias-corrected ones. In the results of future projections, the downscaling technique seems to be more effective in reducing the range of uncertainties. Therefore, BC-RCMs models are chosen to project the future climate condition in the $B R B$. For temperature variables, increasing variation ranges from 0 to $4,8^{\circ} \mathrm{C}$ in comparison with baseline period, which the high temperature region will have higher variation range of increase. For annual precipitation variables, variable range of increase is higher in the large annual precipitation regions, variable range of increase in the rainy season is lower than in the dry season.
\end{abstract}

Keywords: Uncertainty, Climate model outputs, The Ba River basin, Climate change. 